\title{
MENGEKSPLORASI MOTIF BATIK ELEPHANT THAILAND MENGGUNAKAN TEKNIK SHIBORI OLEH SISWA SD BAN KRUA BANGKOK
}

\author{
Belinda Dewi Regina \\ Pendidikan Guru Sekolah Dasar, FKIP, Universitas Muhammadiyah Malang \\ e-mail: belindadewi@umm.ac.id
}

\begin{abstract}
Every country has its own characteristics, both customs and culture. One of them is the country of Thailand which is famous for its elephants and has become an icon. Thailand highly upholds culture, especially in the world of education. Ban Krua Elementary School is a school that is still culturally thick and is an Islamic school in Bangkok. Learning art and culture at the Ban Krua Elementary School, students have introduced elephant animals because they are included in the subject of drawing shapes. During an interview with the SD Krua elementary school teacher, this school had never been taught to make batik. So there is no interesting thing for students from year to year. Looking at the above phenomena, researchers are interested in conducting research "Exploring Thai Elephant Batik Motifs Using the Shibori Technique by Ban Krua Elementary School Students in Bangkok".The purpose of this research is (1) Knowing how to explore elephants into one of the Shibori Techniques of Batik Motives. (2) Knowing the Application of the Elephant Batik Motif in the Shibori Technique. This research is a type of qualitative research with a descriptive approach. The subject of this study, the batik work of students using the Shibori technique with an Elephant motif. This study resulted in: 1) Elephant exploration process became one of the Batik motifs of Shibori technique, namely by observing around the neighborhood of Ban Krua Elementary School, both directly and in literature. After making observations, students draw the face of an elephant by combining other forms around the Ban Krua Elementary School. 2) Application of Elephant batik motifs in the Shibori Technique to produce beautiful wall decorations and tablecloths. By making Batik Teknik Shibori, adding creativity to students, especially in combining colors with objects that have been drawn so as to produce beautiful batik works.
\end{abstract}

Keywords: Exploration, batik motif, Thai Elephant, Shibori Technique

\begin{abstract}
Abstrak: Setiap negara mempunyai ciri khas tersendiri, baik adat istiadat maupun budaya. Salah satunya Negara Thailand yang terkenal dengan gajahnya dan sudah menjadi ikon. Thailand sangat menjunjung tinggi budaya terutama dalam dunia pendidikan. SD Ban Krua merupakan salah satu sekolah yang masih kental dengan budaya serta merupakan sekolah islam yang terdapat di Bangkok. Pembelajaran seni budaya di SD Ban Krua, para siswa sudah dikenalkan binatang gajah karena masuk dalam mata pelajaran menggambar bentuk. Saat wawancara dengan guru SD Bank Krua, sekolah ini belum pernah diajarkan membuat batik. Sehingga tidak ada hal menarik bagi siswa dari tahun ketahunnya. Melihat fenomena diatas, peneliti tertarik melakukan penelitian "Mengeksplorasi Motif Batik Elephant Thailand Menggunakan Teknik Shibori oleh Siswa SD Ban Krua Bangkok". Penelitian ini tujuannya (1) Mengetahui Bagaimana cara Mengeksplorasi Elephant Menjadi Salah Satu Motif Batik Teknik Shibori. (2) Mengetahui Bagaimana Aplikasi Motif Batik Elephant dalam Teknik Shibori. Penelitian ini berjenis penelitian kualitatif dengan pendekatan deskriptif. Subjek dari penelitian ini, karya membatik siswa menggunakan teknik Shibori dengan motif Elephant. Penelitian ini menghasilkan:1) Proses eksplorasi Elephant menjadi salah satu motif Batik teknik Shibori yaitu dengan pengamatan di sekitar lingkungan SD Ban Krua, baik secara langsung maupun studi pustaka. Setelah melakukan pengamatan, siswa menggambar wajah gajah dengan mengkombinasikan bentuk lain yang terdapat disekitar SD Ban Krua. 2) Aplikasi motif batik Elephant dalam Teknik Shibori sehingga menghasilkan hiasan dinding maupun taplak meja yang indah. Dengan membuat Batik berteknik Shibori, menambah kreatifitas bagi siswa terutama dalam mengkombinasikan warna dengan objek yang telah digambar sehingga menghasilkan karya batik yang indah.
\end{abstract}

Kata Kunci: Eksplorasi, motif batik, Elephant Thailand, Teknik Shibori 


\section{PENDAHULUAN}

Pendidikan sangatlah penting bagi kehidupan manusia. Pendidikan sangatlah dibutuhkan, karena tanpa adanya pendidikan kita dapat menjadi bangsa yang gampang dijajah dan mudah di bodohi oleh bangsa lain. Melihat hal tersebut, sangatlah penting bagi kita untuk menanamkan nilai pendidikan mulai usia dini (Hasibuan, 2006:16), sehingga akan lebih mudah bagi kita untuk mengajarkan bagaimana sopan santun, serta menghargai lingkungan yang ada disekitar kita. Pendidikan juga sangat penting untuk bangsa sebagai landasan dasar pembangunan suatu bangsa. Oleh karenanya kita sebagai bangsa yang baik harus mementingkan pendidikan dimanapuin kita berada. Begitu juga dengan kebudayaan seperti membatik. Batik juga harus kita lestarikan keberadaanya supaya tidak diakui oleh negara lain.

Indonesia saat ini sangat terkenal dengan budaya membatiknya hingga ke seluruh pelosok dunia. Di Indonesia batik itu tidak hanya merupakan sekedar batik saja, namun mengandung arti simbolik dengan melambangkan ciri khas di setiap daerah Indonesia. Bangsa indonesia merupakan suatu bangsa yang sangat besar dan terdiri banyak suku didalamnya. Dari berbagai macam suku tersebut sehingga muncullah beragam jenis adat-istiadat, kultur dan budaya. Secara historis, batik berasal dari Jawa (Asti, 2011:20). Batik dibuat sehingga memiliki motif dan memiliki warna yang sesuai ciri khas dari daerahnya. Oleh sebab itu, warna dan motif batik memiliki beraneka ragam sesuai dengan ciri khas daerah masing-masing. Sehingga di setiap daerah memiliki kekhasan masingmasing. Saat ini batik tidak hanya diminati oleh kalangan bangsawan saja, namun siswa sekolahpun menerapkan batik dalam mata pelajaran seni Budaya. Di luar negeri pelajaran seni budaya hanya diajarkan menggambar bentuk saja, seperti di Sekolah Dasar Ban Krua yang merupakan sekolah Islam di Bangkok Thailand. Oleh sebab itu menarik saya untuk mengenalkan Batik didalam pelajaran seni budaya. Batik yang saya ajarkan disana yaitu Batik teknik Shibori dengan motif Elephant. Ini bertujuan supaya batik lebih dikenal bukan hanya di Indonesia tetapi bisa di luar Indonesia. Selain mengenalkan budaya, pembelajaran membatik bertujuan agar siswa tidak bosan dengan mata pelajaran seni yang sudah diajarkan sebelumnya.

Pembelajaran batik teknik Shibori ini dilakukan siswa secara berkelompok, dengan memperhatikan guru kemudian mempraktekkan bagaimana cara pembuatan batik. Sebelum siswa mempraktekkan batik, terlebih dahulu siswa diberi pengetahuan tentang membatik. Dengan dasar sebuah pemahaman yang sangat baik dan benar, proses dalam pelatihan keterampilan karya membatik akan menjadi lebih mudah (Wiyoso, 1995:5).

Dalam hal ini membuat peneliti semakin tertarik bagaimana cara mengeksplore ide motif batik dan mengaplikasikan batik teknik Shibori untuk kelas V SD Ban Krua. Dengan penelitian yang berjudul "Mengeksplorasi Motif Batik Elephant Thailand Menggunakan Teknik Shibori Oleh Siswa SD Ban Krua Bangkok.

\section{METODE PENELITIAN Pendekatan Penelitian}

Penelitian ini berjenis penelitian kualitatif. Dalam penelitian ini menggunakan penelitian deskriptif dengan menggunakan gambaran sistematis. Penelitian ini juga berisi tentang deskripsi data serta berasal dari sebuah wawancara dengan guru serta siswa di kelas V yang terletak di Sekolah Dasar Ban Krua. Penelitian ini bertujuan 
untuk mengetahui cara mengeksplorasi ide motif Elephant teknik Shibori serta mengetahui cara pengaplikasian batik dalam teknik Shibori.

Objek dari penelitian ini adalah cara mengeksplorasi Ide motif Elephant teknik Shibori dan cara pengaplikasian Batik dalam Teknik Shibori. Subjek dalam penelitian ini adalah para siswa kelas V di sekolah Dasar Ban Krua Thailand. Penelitian ini membutuhkan rentang waktu yaitu tanggal 17 Juli sampai dengan 22 Juli tahun 2018. Dalam penelitian ini menghabiskan waktu selama satu minggu. Lokasi penelitian ini terdapat di Sekolah Dasar Ban Krua Thailand. Sekolah Dasar Ban Krua merupakan sekolah Islam yang terletak di Thailand. Siswa Ban Krua memiliki siswa yang asli dari keturunan Thai. Penelitian ini terletak di jalan Thanon Phetchaburi, Ratchathewi, Bangkok Thailand. Jalan yang ditempuh untuk menuju kesana bisa ditempuh dengan menggunakan kendaraan roda 4 . Hal ini dikarenakan lokasi menuju Sekolah Dasar Ban Krua berhadapan langsung dengan jalan raya, sehingga menjadikan sekolah ini strategis untuk dikunjungi dan mudah dicari.

\section{HASIL PEMBAHASAN}

\section{Lokasi Penelitian}

Sekolah Dasar Ban Krua terletak di jalan Thanon Phetchaburi, Ratchathewi, Bangkok 10400, Thailand. Sekolah Ban Krua memiliki sebuah lingkungan yang termasuk nyaman dan aman untuk proses belajar mengajar. Sekolah ini memiliki letak yang strategis karena bersebelahan dengan jalan raya. Selain memiliki lokasi yang strategis, sekolah Ban Krua juga memiliki sebuah bangunan yang luas. Bangunan yang dimiliki banyak sekali dikelilingi oleh pagar besar dan tinggitinggi. Untuk meningkatkan keamanan dan kenyamanan sekolah, karyawan, parkir tamu, guru dan karyawan dibuat dengan terpisah.
Hal ini bertujuan untuk memudahkan untuk lebih mengamankan penjagaan supaya lebih aman dan tentram. Di Sekolah Ban Krua memiliki lebih dari 7 ruangan, dimulai dari kelas 1 hingga kelas 6. Selain itu terdapat ruang tamu, ruang kantor, serta terdapat kantin dimana kantin tersebut digunakan untuk tempat menyediakan makanan bagi para siswa. Sehingga para siswa tidak kesulitan untuk mencari makan dan tanpa keluar dari lingungan sekolah. Di Sekolah Ban Krua para siswa di setiap harinya selalu membawa tempat makan dan tempat minuman sendiri-sendiri pada saat jam makan siang. Masing-masing siswa mendapatkan jatah minuman setiap harinya.

Di Sekolah Ban Krua terdapat ruang outdor, dimana para siswa sering melakukan praktek seperti proses pembelajaran yang menggunakan alam sebagai bahan penelitiannya. Di ruang outdor tersebut disampingnya berdiri bangunan masjid yang biasa para siswa melakukan sholat berjamaah bersama saat jam istrahat berlangsung. Di Sekolah Ban Krua $50 \%$ beragama islam dan 50\% lainnya beragama hindu. Meskipun mereka berbeda agama, mereka saling menghargai antara satu sama dengan yang lainnya. Siswa Ban Krua 100\% berasal dari keturunan Thai, dimana Thai itu asli bangsa Thailnad.Guru yang berada di Sekoalh Ban Krua sebanyak 15 orang, mereka memiliki keahlian masingmasing dalam mendidik siswa. Salah satu keahlian yang dimiliki oleh guru yaitu dalam bidang seni.

Guru seni di Sekolah Ban Krua sudah tidak diragukan lagi dalam mengajar seni. Mata pelajaran seni di Sekolah Ban Krua sebatas menggambar bentuk dan benda-benda disekitar sekolah tanpa adanya perubahan di setiap pembelajarannya. Sehingga mengakibatkan siswa kurang begitu berminat ataupun tertarik dalam mata pelajaran seni. Dalam hal ini dibuktikan dengan siswa ramai pada saat 
pembelajaran berlangsung. Sehingga membuat siswa lain merasa terganggu dengan keramaian para siswa yang lainnya. Hal ini juga membuat siswa kurang produktif dalam menangkap pembelajaran yang telah diterangkan oleh guru.

Dengan adanya situasi yang terjadi di Sekolah Ban Krua tersebut membuat kami tertarik untuk mengadakan penelitian dimana kami akan mengeksplorasikan motif batik Elephant sebagai ciri khas binatang yang ada di Negara Thailand. Dalam mengekplorasikan batik ini dapat mengajarkan siswa tentang berkesenian membatik terutama siswa kelas $\mathrm{V}$ sekolah dasar. Selain itu mengajarkan siswa belajar kepekaan dengan lingkungan sekitarnya, karena pembelajaran ini dapat mendidik dan membimbing siswa untuk berkreatifitas. Hal ini juga dapat membimbing siswa dalam menghasilkan sebuah produk unggulan sebuah batik yang memiliki nilai seni cukup tinggi. Selain membimbing siswa juga mendidik siswa untuk lebih giat lagi dalam proses pembuatan batik. Selain juga untuk mengekplorasi juga untuk memvisualisasikan batik shibori supaya siswa lebih kreatif. Siswa diajarkan membatik mulai dari tahap awal sampai dengan tahap finishing. Motif-motif yang diajarka dalam pembuatan batik ber teknik Shibori ini adalah berupa motif Elephant dengan tumbuhan yang berada disekitar sekolah Ban Krua.

Para siswa membuat motif yang ada disekitar sekolah, kemudian mengembangkan motif tersebut dengan sekreatif mungkin, sehingga akan menghasilkan motif yang indah serta unik. Pembuatan batik berteknik Shibori ini seperti pembuatan batik ikat pada umumnya namun yang menarik dari motif Batik ini karena adanya ikatan motif yang menyerupai kepala gajah yang membuat unik ketika melihatnya. Selain banyak keunikan ataupun kelebihan dari pembuatan batik teknik Shibori ini, namun juga memiliki kelemahan didalamnya.

Kelemahan dalam pembuatan batik teknik Shibori yaitu bahan yang pewarna yang terdapat di Thailand tidak ada, karena semua didatangkan dari Indonesia. Cara lain untuk mengatasi bahan pewarna supaya bisa membuat batik yaitu menggunakan bahan pewarna alam. Hal ini bisa membatu pewarna pengganti remasol yang dipakai untuk membuat batik teknik Shibori. Seluruh karya yang telah dihasilkan dalam membuat batik teknik Shibori dipajang didindingdinding ruang sekolah, sehingga menambah koleksi karya tradisional asli Indonesia yaitu batik teknik Shibori.

\section{Mengeksplorasi Elephant menjadi salah satu Motif Batik Teknik Shibori.}

Pemilihan suatu tema dijadikan sebagai dasar dalam menentukan sebuah ide serta sebuah konsep pembuatan karya seni. Elephant serta batik saat ini menjadi sebuah pusat perhatian dari penulis dan nantinya akan dijadikan sebagai dasar dalam pembuatan sebuah karya seni batik dengan teknik Shibori. Elephant atau kepala gajah merupakan ciri khas binatang yang terdapat di negara Bangkok Thailand. Sedangkan batik sendiri merupakan suatu kebudayaan yang sangat berkembang di Indonesia khususnya pulau jawa dan secara turuntemurun.

Insipirasi dalam proses pembuatan karya berasal dari pengamatan langsung disekitar lingkungan SD Ban Krua, melihat flora kesukaan, peristiwa maupun kenangan (pengalaman) serta mencari referensi berupa studi pustaka. Hal ini bertujuan untuk mengenalkan tentang lingkungan dan dapat mengenalkan tentang binatang gajah sebagai hewan khas dari Thailand.

Motif batik ini merupakan hasil bentuk ekspresi diri dari siswa SD kelas $\mathrm{V}$, sehingga sebuah karya yang telah dihasilkan telah sesuai dengan apa yang 
sudah menjadi karakter dari setiap siswa serta sebagai wujud dari jati diri siswa. Dalam proses membuat karya seni membatik yang dihasilkan, terdapat beberapa unsur sebuah ekspresi dengan mengungkapkan emosional dari siswa sehingga dapat mewujudkan sebuah karya seni yang indah dan menarik.

Motif batik teknik Shibori ini mengacu pada bentuk visual sebuah gajah yang telah diamati langsung oleh siswa. Dalam hal ini siswa mengamati langsung maupun dengan studi pustaka. Setelah mendapatkan data yang sekiranya dibutuhkan, langkah selanjutnya yaitu siswa memasuki metode penciptaan. Metode penciptaan ini siswa membuat sketsa karya diatas kain khusus membatik yaitu berjenis primisima menggunakan pensil berukuran 2B sesuai dengan kreatifitas siswa (masih dalam motif utama yaitu binatang gajah), lalu kemudian membuat ikatan-ikatan mengikuti sketsa yang telah dibuat menggunakan karet gelang maupun tali rafia serta memberi motif berbentuk lingkaran menggunakan kelereng.

Gajah disini merupakan motif utama dalam pembuatan batik dengan menggunakan teknik Shibori. Sedangkan motif selain gajah merupakan motif tambahan seperti bentuk batu, serta flora maupun fauna yang terletak disekitar motif gajah.

Berikut adalah karya siswa dalam membatik teknik Shibori dengan motif utama gajah sebagai ciri khas dari negara Thailand.

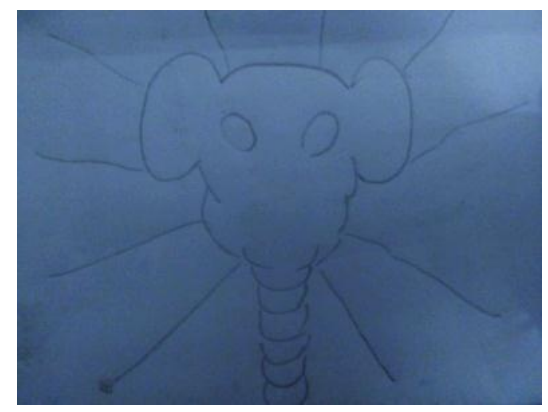

Gambar 1. Desain batik teknik Shibori dengan motif utama kepala gajah dan motif tambahan garis.
Desain ini dibuat dengan menggunakan motif utama kepala gajah, dan motif tambahan berupa garis lurus. Batik motif Elephant ini dikerjakan secara kelompok dengan mengamati lingkungan sekitar dan juga penambahan dari studi pustaka. Motif tambahan berupa garis terinspirasi dari bentuk lurus seperti kaki meja kursi yang terdapat disekitar sekolah. Mereka bekerja secara berkelompok sehingga desain yang dihasilkan tidak hanya berasal dari pemikiran satu siswa saja, namun 7 siswa. Jadi wajar saja jika bentuknya dalam setiap kelompok satu dengan kelompok lain berbeda.

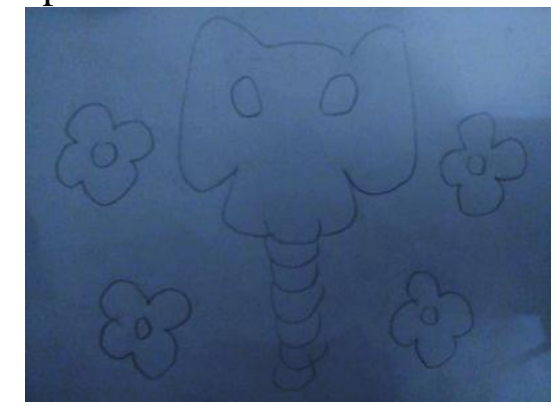

Gambar 2. Desain batik teknik Shibori dengan motif utama kepala gajah dan motif tambahan bunga.

Dalam pembuatan desain batik, motif utamanya yaitu gajah, sedangkan motif tambahannya berupa bunga. Siswa bekerja secara berkelompok sehingga menghasilkan sebuah batik yang menarik sesuai dengan kreatifitas mereka masingmasing tetapi tetap menggunakan bentuk gajah sebagai motif utamanya dengan mengamati daerah sekitar tempat tinggal mereka. Selain motif utama ada juga motif tambahan berupa bunga terinspirasi dari tanaman yang tumbuh sekitar dilingkungan sekolah.

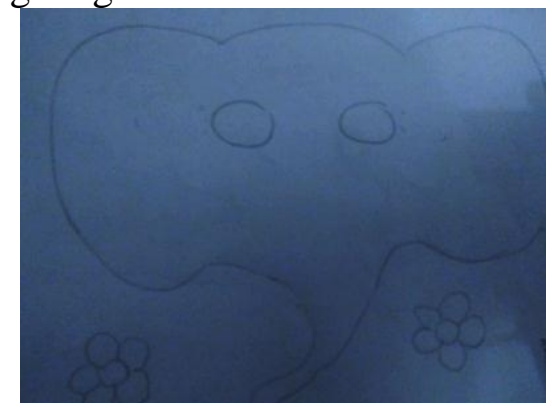

Gambar 3. Desain batik teknik Shibori dengan motif utama kepala gajah dan motif tambahan bunga. 
Pembuatan batik teknik Shibori ini dibuat siswa dengan berkelompok dan menjadikan siswa lebih terasah bakat menggambarnya serta mampu menjadikan siswa sebagai pribadi yang sabar karena diharuskan rapi dalam pembuatan desain batik. Desain batik teknik Shibori ini motif utama bergambar kepala gajah yang cenderung lebih besar hampir menutup kain. Mereka terinspirasi dari pengamatan benda yang berada di daerah tempat tinggal, kemudian mereka gambar diatas kain menjadi bentuk yang indah. Motif tambahan dalam pembuatan batik teknik Shibori ini berupa bunga yang terinspirasi dari kesukaan siswa karena kecantikan bunga.

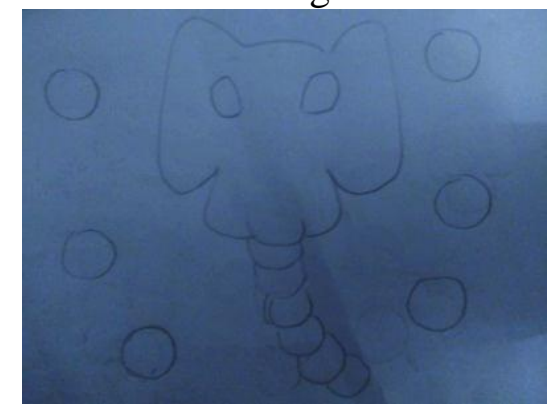

Gambar 4. Desain batik teknik Shibori dengan motif utama kepala gajah dan motif tambahan garis.

Desain dalam pembuatan batik ini memiliki motif utama kepala binatang gajah, dimana gajah ini merupakan ciri khas hewan dari Thailand. Motif tabahannya berupa bentuk lingkaran seperti batu-batuan kerikil yang berasal dari pengamatan langsung siswa yang berada disekitar lingkungan sekolah. Pembuatan batik ini dikerjakan secara kelompok, mereka membentuk beberapa kelompok supaya gambar yang dihasilkan berasal dari beberapa pemikiran siswa. Hingga akhinya membentuk gambar kepala gajah dengan motif disekelilingnya berupa bebatuan sebagai motif tambahan.

\section{Aplikasi Motif Batik Elephant Dalam Teknik Shibori}

Gajah dan batik menjadikan pusat perhatian penulis yang dijadikan dasar dalam pembuatan karya seni yaitu batik dengan teknik Shibori yang diaplikasikan menjadi sebuah hiasan dinding serta taplak meja yang unik dan menarik. Bahan yang diguanakan dalam pembuatan batik ini yaitu kain khusus untuk membatik berjenis primisima. Selain karena khusus untuk membatik, kain ini juga mempertimbangkan tingkat kenyamananya.

Teknik yang digunakan dalam membuat batik yaitu teknik membatik Shibori dengan diikat-ikat sesuai desain yang dibuat sebelumnya. Dalam berproses membuat batik, perlu sekali mempertimbangkan langkah yang bisa mempermudah kedalam proses perwujudtannya yaitu hiasan dinding maupun taplak meja. Sehingga mampu meminimalisirkan berbagai kendala yang nantinya dapat menghambat sekali proses pembuatan sebuah karya membatik, serta karya yang dihasilkan tersebut sesuai dengan apa yang diharapkan. Batik yang dihasilkan siswa banyak terinspirasi dari berbagai macam sumber, baik itu pengamatan langsung maupun apa saya yang mereka sukai seperti bunga, peristiwa maupun kenangan yang telah dimiliki saat ini.

Berikut ini pengaplikasian siswa dalam pembuatan batik motif Elephant dalam teknik Shibori :

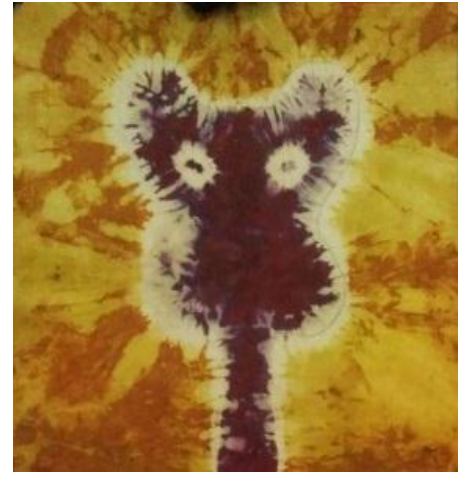

Gambar 5. Aplikasi batik teknik Shibori berupa hiasan dinding dengan motif kepala gajah, motif tambahan garis lurus.

Judul karya : Elephant ang line

Teknik : Shibori

Teknik Pewarnaan : Remasol

Bahan kain: Primisima 
Ukuran : 100x100 cm

Tahun : 2018

Tinjauan khusus dalam karya batik ini adalah motif Elephant teknik Shibori diaplikasikan menjadi hiasan dinding yang indah. Warna kuning dan orang mendominasi kain dengan teknik ikat. Kepala gajah diberi warna coklat tua supaya kelihatan lebih menonjol. Makna dari warna coklat yaitu memberi kesan hangat, nyaman serta aman. Sedangkan wajah gajah melambangkan penyangga alam semesta dengan motif tambahan garis melambangkan ketenangan dan kedamaian.

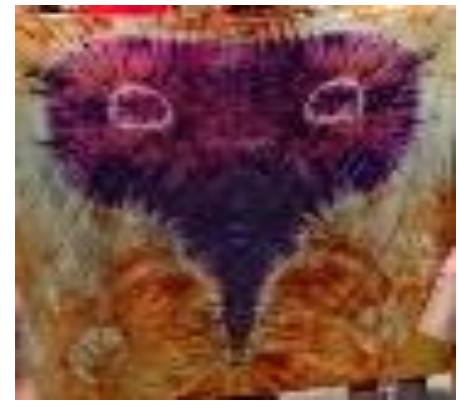

Gambar 6. Aplikasi batik teknik Shibori berupa hiasan dinding dengan motif kepala gajah, motif tambahan bebatuan.

Judul karya :Elephant between rocks

Teknik : Shibori

Teknik Pewarnaan : Remasol

Bahan kain: Primisima

Ukuran : 100x100 cm

Tahun : 2018

Tinjauan khusus dalam pembuatan batik teknik Shibori ini yaitu pengaplikasian kain kedalam bentuk hiasan dinding dengan motif Elephant sebagai motif utama dalam pembuatan batik teknik Shibori.Warna dalam pembuatan batik ini didominasi warna biru tua. Biru melambangkan ketenangan dan kesegaran. Motif tambahan batik teknik Shibori ini berbentuk bebatuan yang berada disekitar kepala gajah, motif ini terinspirasi dari batu batuan yang berada disekitar lingkungan sekolah. Batu melambangkan dasar-dasar yang kokoh.

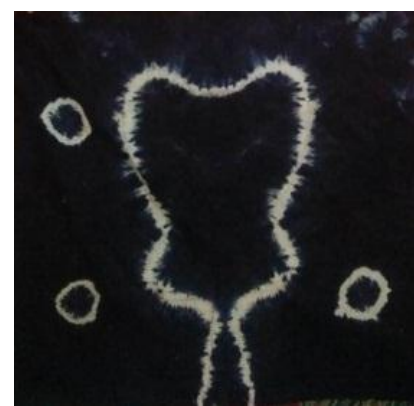

Gambar 7. Aplikasi batik teknik Shibori berupa hiasan dinding dengan motif kepala gajah, motif tambahan bunga.

Judul karya : The flowers surround the elephants

Teknik : Shibori

Teknik Pewarnaan : Remasol

Bahan kain: Primisima

Ukuran : 100x100 cm

Tahun : 2018

Tinjauan khusus dalam pembuatan batik ini adalah mengaplikasikan batik motif Elephant teknik Shibori dalam bentuk taplak meja. Motif ini didominasi gambar kepala gajah yang besar dengan motif tambahan bunga-bunga disekitar wajah gajah. Warna yang mendominasi alam batik tersebut yaitu warna coklat bercampur orange. Orange melambangkan keanggunan sedangkan wajah gajah bewarna ungu melambangkan kewanitaan, karena yang membuat batik kelompok ini terdiri dari perempuan semua. Bunga-bunga disekitar wajah gajah melambangkan cinta dan kasih sayang. Hal ini bisa diartikan bahwa siswa saling menyayangi dalam proses berkarya batik.

Berikut adalah dokumentasi poto bersama siswa SD Ban Krua Bangkok mulai dari proses pembuatan karya batik teknik Shibori sampai dengan tahap finishing. Siswa sangat gembira karena sebelumnya belum pernah diajarkan membatik dengan motif Elephant sebagai ciri khas binatang dari negara Thailand. 


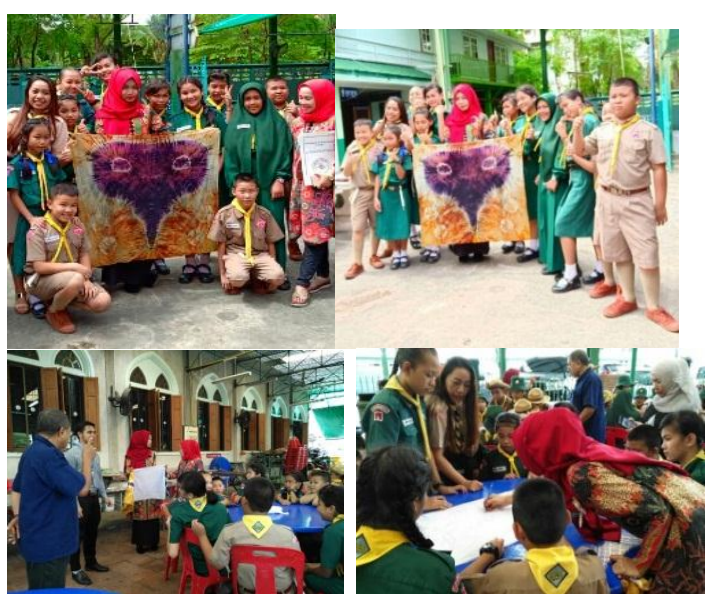

Gambar 8. Dokumentasi poto bersama siswa SD Ban Krua Thailand

\section{KESIMPULAN DAN SARAN Kesimpulan}

Pemilihan sebuah tema seperti gajah sebagai icon negara Thailand dan batik sebagai ciri khas budaya dari Indonesia, apabila dikombinasikan akan membentuk keanekaragaman budaya. Dalam pembuatan batik teknik Shibori ini menjadikan siswa lebih kreatif dan menciptakan karakter dari setiap siswa serta merupakan bentuk ekspresi diri dari setiap siswa. Dengan memanfaatkan lingkungan sekitar merupakan salah satu sarana dalam mengenalkan siswa dengan alam serta ciri khas yang dimiliki dari negara tersebut yaitu binatang gajah. Dari pembuatan batik teknik Shibori ini dapat diaplikasikan kedalam bentuk hiasan dinding serta taplak meja yang indah dan menarik. Siswa menjadi senang dan semakin semangat dalam menimba ilmu khususnya pembelajaran seni budaya di SD Ban Krua Bangkok Thailand.

\section{Saran}

Cara mengekplorasi Batik teknik Shibori yaitu dengan menggambil motif berupa bentuk kepala gajah sebagai simbol negara Thailand. Gajah disini diambil karena dianggap binatang kuat dalam jangka waktu yang lama dan memiliki umur yang panjang.

Bagi guru, cara mengeksplorasi ide motif Elephant dengan menggunakan teknik Shibori tidak hanya berfokus pada saat pembelajaran berlangsung atau pada saat menerangkan didepan kelas. Namun eksplorasi ide motif dapat dilakukan dengan melakukan studi pustaka dan bisa dilakukan dengan studi lapangan. Setelah data diperoleh, kemudian siswa membuat desain atau motif dengan cara membuat ikatan pada kain yang nantinya akan tercipta karya berupa wajah gajah menggunakan teknik Shibori. Hal ini bisa atau patut untuk dicoba supaya siswa mampu berekpresi dengan pewarna batik selain pewarna naptol serta dapat menambah banyak pengetahuan siswa tentang berbagai macam pewarna batik serta penggunaannya.

Untuk siswa, tetaplah semangat dalam belajar, setelah mengenal batik dengan teknik Shibori ini dapat menjadi inspirasi siswa kedepannya dalam pembuatan batik yang lebih berguna dan dapat dijual sebagai cindera mata khususnya di negara Thailand. Selain itu siswa supaya banyak berlatih sesering mungkin dalam membuat batik supaya mendapatkan hasil yang memuaskan, unik dan menarik.

\section{DAFTAR ISI}

Hasibuan \& Moedjiono. 2006. Proses Belajar Mengajar. Bandung: PT Remaja Rosdakarya.

Asti Musman \& Ambar B.Arini. 2011. Batik: Warisan Adiluhung Nusantara. Yogyakarta: G-media.

Yudoseputro, Wiyoso. 1986. Pengantar Seni Rupa Islam Indonesia. Bandung: Angkasa.

Alfian. 2014. Memonitor Komitmen Pasti Kegiatan Eksplorasi. Buletin SKK : Migas Bumi.

Murtihadi. $1979 . \quad$ Pengetahuan Tekhnologi Batik. Jakarta: Departemen Pendidikan dan Kebudayaan.

Susanto, S.K. Sewan. 1981. Teknologi Batik Seri Soga Batik. Departemen Perindustrian R.I Badan Penelitian dan Pengembangan industri. Balai Besar Penelitian dan 
Pengembangan Industri Kerajinan Batik: Yogjakarta.

A.N. Suyanto. 1986. Sejarah Batik Yogyakarta, Merapi, Yogyakarta, 2002, hlm. 2.; bandingkan dengan Endik S., Seni Membatik, Safir Alam, Jakarta. 